\title{
Precise Burst Synchrony in the Superior Colliculus of the Awake Cat during Moving Stimulus Presentation
}

\author{
Quentin Pauluis, ${ }^{1}$ Stuart N. Baker, ${ }^{2}$ and Etienne Olivier ${ }^{1}$ \\ ${ }^{1}$ Laboratory of Neurophysiology, School of Medicine, Université Catholique de Louvain, B-1200 Brussels, Belgium, and \\ 2Department of Anatomy, Cambridge University, Cambridge, United Kingdom CB2 3DY
}

This study aimed to characterize the synchrony that occurs between cell discharges in the superior colliculus of the awake cat. We trained cats to perform a visual fixation in the presence of a visual moving stimulus and then recorded 686 pairs of neighboring cells in the superior colliculus during task performance. A new method to assess the significance of precise discharge synchronization is described, which permits analysis of nonstationary data. Of 181 pairs with sufficient data for quantitative analysis, 125 showed a cross-correlation histogram $(\mathrm{CCH})$ with features assessed as significant using this approach. $\mathrm{CCHs}$ frequently showed an isolated central peak (41 of 125) or a peak flanked by one or two troughs (68 of 125), and in a few cases an oscillatory pattern of $\sim 65 \mathrm{~Hz}$ (16 of 125). This is in contrast to the oscillation frequency reported for the visual cortex and shows that oscillations in the superior colliculus probably arise from a cortex-independent mechanism.
Our method also permits direct quantification of the correlation shift predictors, assessing precise time locking of spikes to the stimulus. Only 1 of 125 cross-correlation shift predictors had a significant central peak, meaning that most of the $\mathrm{CCH}$ features were not related to cell discharges time-locked to the stimulus presentation.

Further investigation using a burst-jittering method showed that synchrony in the superior colliculus is attributable to precise synchronization of short bursts of spikes. Such synchrony could be related to the network dynamics and the common inhibitory feedback from local interneurons, which would act as temporal selectors of the cells with greatest or fastest response.

Key words: correlation analysis; coincident event; fast oscillations; spike; motion-processing; stimulus-locked responses
Synchronous neuronal activity at the millisecond time scale has been described in the mammalian visual cortex (Griffith and Horn, 1963) and in many other regions of the brain (Singer and Gray, 1995). Although this phenomenon has aroused interest for some time, its functional significance remains uncertain and has become an object of speculation and controversy (Usrey and Reid, 1999). Synchrony could be related to information transfer by synfire chains (Abeles, 1991), information storage in potentiated synapses (Singer, 1995; Whittington et al., 1997), a time advance coding scheme (Hopfield 1995, 1996), tag transmission in binding theory (Roelfsema and Singer, 1998), or to timed neuronal selection for temporal pattern recognition (Laurent, 1996; Parodi et al., 1996). Similarly, coincident bursts have also been suggested to play a role in synaptic plasticity and information processing (Lisman, 1997).

Determining the time during an experiment when synchrony occurs could shed light on its possible function (Vaadia et al., 1995; Riehle et al., 1997). However, this is a difficult statistical problem, because it requires a method capable of quantifying the excess of synchronous spikes, termed coincident events (CEs), even when the neural firing rates covary with the animal's per-

\footnotetext{
Received July 6, 2000; revised Oct. 13, 2000; accepted Oct. 16, 2000.

This work was supported by a British Council-Commissariat Général aux Relations Internationales de la Communauté Française de Belgique travel grant. S.N.B. is supported by the United Kingdom Medical Research Council, Christ's College (Cambridge, UK), and The Wellcome Trust. We thank Anne-Marie Rona for excellent technical assistance in preparing histology.

Correspondence should be addressed to Dr. Quentin Pauluis, Laboratory of Neurophysiology, Université Catholique de Louvain, Avenue Hippocrate 54, B-1200 Brussels, Belgium. E-mail: pauluis@nefy.ucl.ac.be.

Copyright (C) 2001 Society for Neuroscience $0270-6474 / 01 / 210615-13 \$ 15.00 / 0$
}

formance, behavior, or attention (Pauluis and Baker, 2000). Without such precise quantification, it is not possible to show that the information provided by the CEs differs from that contained by the firing rate variation.

The superior colliculus (SC) has long been known as a sensorimotor interface that controls rapid orientation movements (Sparks, 1986; Grantyn, 1988). The ventral part of the superficial laminae of the SC receives direct afferent input from the retina and visual cortex layers $\mathrm{V}$ and VI pyramidal cells (magnocellular pathway). Cortical projections maintain topographic alignment with the retinal input, so that the central $10^{\circ}$ of the visual field are represented proximally by $>30 \%$ of the SC. Cells in the superficial and intermediate layers are visually responsive, exhibit a phasic response to the onset and offset of a stationary spot of light, and respond vigorously to stimuli moving at $0.5-30^{\circ} / \mathrm{sec}$ (sometimes up to $800^{\circ} / \mathrm{sec}$ ). Conversely, the response of cells in deep layers exhibits dramatic adaptation to repetitive stimulation (Sparks, 1986; Grantyn, 1988).

The visual processing of moving visual stimuli performed in the SC suggests that, as in the visual cortex, the SC may be a structure in which synchrony is important for information processing. However, collicular and corticotectal multiunit crosscorrelations observed in the anesthetized cat exhibit much broader peaks than in the cortex (average width at half height, 51 msec; Brecht et al., 1998). Such broad temporal dispersion is thought to be related to a simultaneous activation of both cells or to the presence of large bursts in their discharges, but not especially to a temporally precise coding (Nelson et al., 1992; Nowak et al., 1995).

Given the major role of the SC in gaze and attention orienta- 
tion (Goldberg and Wurtz, 1972; Wurtz et al., 1982; Robinson and Kertzman, 1995), we studied spike train correlations in the $\mathrm{SC}$ of awake cats. The animals performed a fixation task to a central target while a light spot moved in the visual field. We used new quantification methods that relied on instantaneous discharge probability estimates to calculate the expected correlation on a single-trial basis (Pauluis and Baker, 2000).

A preliminary account of this work has been presented previously in abstract form (Pauluis et al., 1999).

\section{MATERIALS AND METHODS}

Experiments were performed on two adult cats selected after a few weeks of training on gaze orientation tasks. The care and use of animals was in accordance with the guidelines of the Society for Neuroscience and the American Physiological Society.

\section{General}

Two cats were prepared for chronic gaze recording by undergoing a first surgery. Anesthesia was induced with xylazine $(2 \mathrm{mg} / \mathrm{kg}$, i.m.) and, after $20 \mathrm{~min}$, with ketamine hydrochloride $(10 \mathrm{mg} / \mathrm{kg}$, i.m. $)$. Deep anesthesia was maintained throughout with additional injections of both drugs. A scleral search coil (three turns of 20 -mm-diameter Teflon-insulated stainless steel wire; Cooner Wire Company, Chatsworth, CA) was implanted under the conjunctiva. The animal was placed in a Horsley-Clarke apparatus, and a head implant was constructed from dental cement and anchored to the skull with stainless steel screws. A fixation device was embedded in dental cement to fix the head during experiments.

After recovery from the surgery, cats underwent a second stereotaxic procedure under deep anesthesia. A craniotomy was performed to allow access of microelectrodes into both SCs, and a stainless steel recording chamber was added to the head implant on the midline at stereotaxic coordinate anterior, +2 .

\section{Behavioral paradigms}

Cats were trained to perform fixation and saccade tasks for food reward. The target spots were projected on a tangential screen by oscilloscopes controlled with an 80486 personal computer (digital-to-analog converter frequency; $100 \mathrm{~Hz}$ ).

Moving stimulus paradigm. All trials started with an auditory click followed after $300 \mathrm{msec}$ by the appearance of a small fixation point (FP) of $0.5^{\circ}$ and a larger stimulus point (SP) (disk $\sim 3.0^{\circ}$ ) both at the center of the visual field (Fig. 1A). The cat had $1200 \mathrm{msec}$ to begin fixating and was required to maintain fixation for $500-1200 \mathrm{msec}$ (Fig. $1 C$ ). Then, the SP moved slowly toward the periphery with fixed velocity $\left(5-70^{\circ} / \mathrm{sec}\right)$, amplitude $\left(5-35^{\circ}\right)$, and direction, which could be chosen either specifically or randomly (Fig. $1 B$ ). The SP was the stimulus for the recorded cells. At the end of the ramp, the SP was switched off for $300 \mathrm{msec}$. A new SP appeared then at the center and started to move after $60 \mathrm{msec}$. This was repeated up to four times. During the whole paradigm the cat was not allowed to follow the stimulus and had to maintain fixation within $3^{\circ}$ of the FP to receive a food reward.

Cats were typically capable of $2 \mathrm{hr}$ of sustained task performance, performing a total of $300-800$ trials in blocks of $20-80$.

\section{Recording and data collection}

Neuronal discharge was recorded extracellularly with two commercially available tungsten microelectrodes (impedance, $0.15-0.6 \mathrm{M} \Omega$ at $1 \mathrm{kHz}$; FHC, Bowdoinham, ME). The two electrodes were mounted on a double hydraulic microdrive (model MO-95B; Narishige, Tokyo, Japan) fitting a single recording chamber and were driven independently. Electrode penetrations were made vertically through a single guide tube (21 gauge; horizontal distance between electrode tips, $>300 \mu \mathrm{m}$ ). The guide tube was inserted afresh each session through the dura to a depth of $5 \mathrm{~mm}$ above the SC. Neural activity was conventionally amplified (gain, 5000 or 10,000; Neurolog NL-100 and NL-104; Digitimer), filtered (300 Hz to 6 $\mathrm{kHz}$; Neurolog NL-125; Digitimer), and displayed. System noise level was $30 \mu \mathrm{V}$ because of the magnetic search coil fields. Cross-talk between the two channels was never observed.

Eye position was measured with the magnetic search coil technique (magnetic field frequencies, 50 and $75 \mathrm{kHz}$ ). The target and stimulus positions were generated by an 80486 personal computer and data acquisition card (model AT-MIO-16E; National Instrument) that also drove the food reward pump and controlled a constant current stimulus isolator (WPI) for electrical stimulation.

The two independent electrodes were positioned in the SC just below the first layer of spontaneously active cells in dim light. As the track was continued deeper, cell discharges showed more and more adaptation to the visual stimulation, preventing reliable recording for more than a few trials. For this reason, most of the cells were recorded in the superficial and intermediate layers (a depth of $0.5-2 \mathrm{~mm}$ below the SC surface).

After a recording session, if the track location was new or if the electrode location was uncertain, we used a stimulation paradigm. After initial fixation of a single FP in the center, the FP was turned off and, after an interval of $50 \mathrm{msec}$, a stimulation train was delivered $(500 \mu \mathrm{sec}$ pulse width; $200 \mathrm{~Hz} ; 200 \mathrm{msec}$ duration; $20 \mu \mathrm{A}$ ). At the end of the stimulation train, a new target appeared randomly $10^{\circ}$ to the right or to the left of the FP, and the cat had to fixate this new target for food reward. The direction and amplitude of evoked short-latency saccadic eye movements permitted precise assessment of the electrode position (Roucoux and Crommelinck, 1976).

All of the data related to the gaze and stimulus positions, to the stimulation, and to the reward were digitized at $2 \mathrm{kHz}$, whereas the extracellular activities were sampled at $20 \mathrm{kHz}$ (Pentium-Pro $200 \mathrm{MHz}$; model AT-MIO-64-E3; National Instruments). Some data files were transferred immediately after the set of trials onto another computer (Pentium-Pro $200 \mathrm{MHz}$ ) to assess the fine temporal relationship between the spike trains. If the cell discharges were not correlated, they were discarded after a few sets. At the end of the recordings for each day, raw data were stored on digital compact disks for further off-line analysis.

In the final recording session, electrolytic lesions were made with stainless steel electrodes to mark the SC ( $20 \mathrm{sec}, 20 \mu \mathrm{A}$ anodal pulse). The animal was then anesthetized with xylazine $(2 \mathrm{mg} / \mathrm{kg}$, i.m. ) followed by pentobarbital sodium $(40 \mathrm{mg} / \mathrm{kg}$, i.p.). After transcardial injection of heparin, the animal was perfused with $0.9 \%$ saline and then with potassium ferrocyanate diluted in neutral formalin, to color iron deposits. The brain was removed and placed into a solution of formalin with 15 and then $30 \%$ sucrose until it sank. The SC was blocked, frozen, and cut into $30 \mu \mathrm{m}$ transversal sections. One section of three was mounted onto chrome-alum-coated slides. Postmortem histological processing confirmed that the marker lesion sites were located in the anterior two-thirds of the SC at the expected depth.

\section{Data analysis}

To remove movement artifacts and to sort two or more spike waveforms, we used a program based on multiple level discriminators set sequentially on a plot of superposed spike waveforms (Matlab 5.0). We compared this simple method to a more time-consuming principal component analysis (Eggermont, 1990), and they appeared equally efficient. To ensure that a single cell was recorded, an autocorrelation histogram $(\mathrm{ACH})$ was constructed $(0.1 \mathrm{msec}$ bin width). The waveform was attributed to a single cell only if the measured absolute refractory period was at least $0.75 \mathrm{msec}$ [minimum interval observed by DeBusk et al. (1997) in the cat striate cortex was $0.73 \mathrm{msec}$. From this processing, it was usually possible to isolate one or more waveforms from a single channel and to classify them as originating from a single or multiple units. No attempt was made to separate overlapping spikes. All the waveforms from a given electrode that did not satisfy the absolute refractory period criterion were pooled together into one channel of multiunit activity.

Before considering the temporal relationship between two different cell discharges, we checked whether the same cells could have been recorded on both electrodes simultaneously. This was achieved by a high-precision cross-correlation histogram $(\mathrm{CCH})(0.1 \mathrm{msec}$ bin width; lags, $2 \mathrm{msec}$ ). If the same cell was recorded on both electrodes, it is expected that the $\mathrm{CCH}$ peak would be very narrow and very high. There could be a short time lag because the spike waveforms could be slightly different. Nine recordings were excluded from the analysis because the $\mathrm{CCHs}$ exhibited a very narrow central peak (0.1-0.2 msec width).

We also characterized the interspike interval (ISI) distribution by the proportion of ISIs shorter than $3 \mathrm{msec}$. This proportion was used by Gray and McCormick (1996) to characterize the chattering cells that had $27.5 \pm 10.8 \%$ of their ISIs shorter than $3 \mathrm{msec}(n=11)$. Although this proportion has been previously applied to single-unit recordings, we extended its use to the multiunit activities for descriptive purpose only, because only a small number of different cells were present in a single channel of multiple unit activity thanks to the spike wave discrimination. The term "bursting train" is used here to describe the recordings in which $\geq 25 \%$ of the ISIs were shorter than 3 msec. 


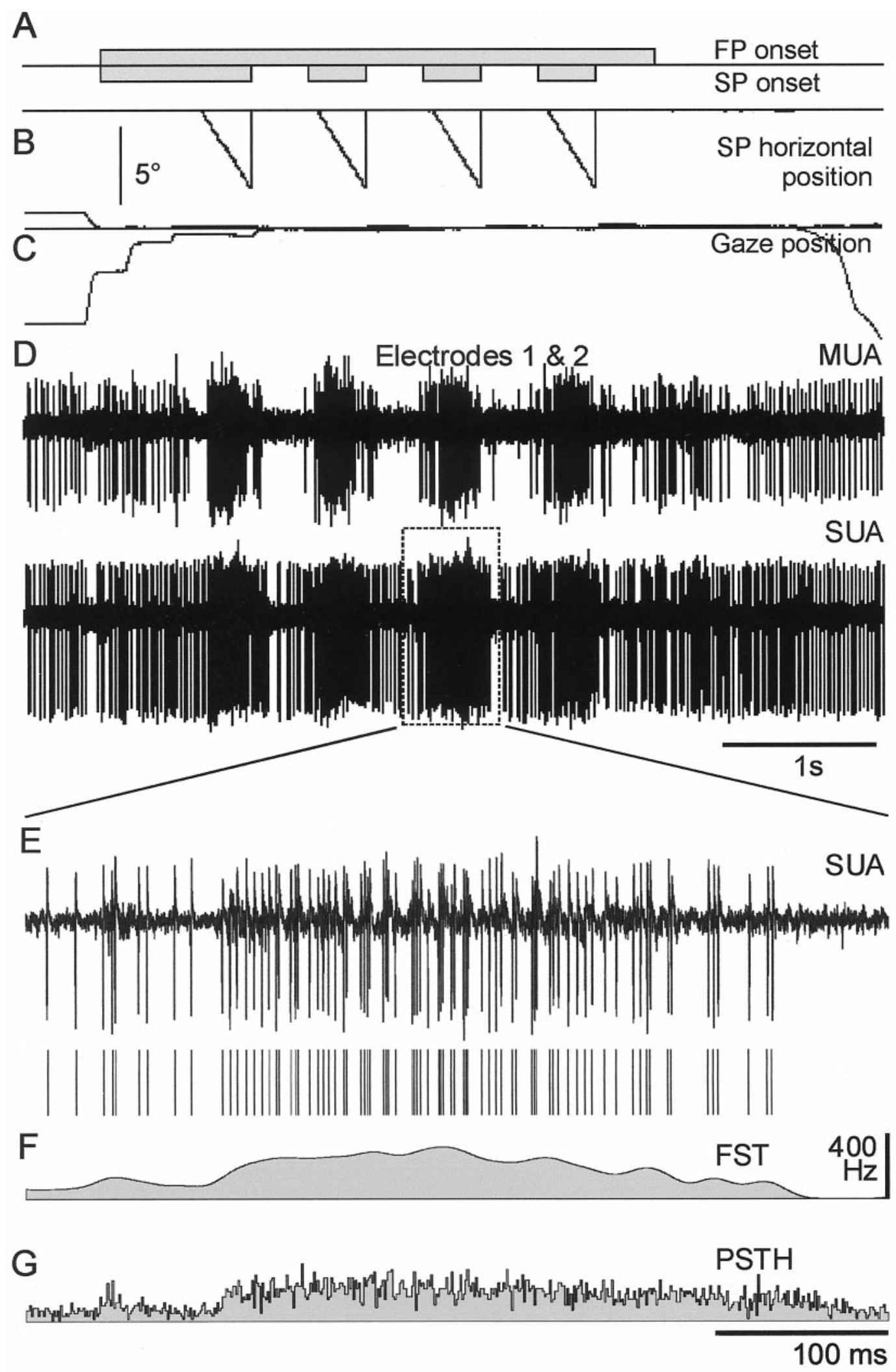

Figure 1. Set up and instantaneous discharge probability estimates. A light spot was presented in the center of the screen and was moved at a uniform velocity $(15 \% \mathrm{sec})$ toward the periphery while the cat was continuously fixating another central point. The onsets of the fixation point $(F P)$ and stimulus point $(S P)$ are shown in $A$. During the fixation task, the SP was moved toward the periphery, as illustrated in $B$. The FP and eye positions are presented in $C$. Cellular activities were recorded from two independent electrodes $(D)$. Result of spike discrimination $(E)$ is shown for a single stimulus presentation. After window discrimination, this train was classified as a single-unit activity, and the other was classified as a multiunit activity. In this study, the estimate of the instantaneous discharge probability $(F)$ is the spike train $(E)$, filtered with a 10 msec Gaussian kernel (filtered spike train). This measure is contrasted with the commonly used PSTH $(G)$ calculated from 80 trials which, in this case, underestimates the discharge probability because the data were not stationary during the 80 trials, as in many experiments on awake animals. 
Other analysis always took place during a period that started $80 \mathrm{msec}$ after the movement beginning, that is after the strongest effect in the cell discharge caused by movement onset, and ended at the movement offset, that is before the offset response.

Instantaneous discharge probability. To determine the significance of cross-correlation peaks, one approach is to assume that the timedependent discharge probability of each cell is equal to its peristimulus time histogram (PSTH). This would correspond to the joint peristimulus time histogram (JPSTH) method (Palm et al., 1988; Aertsen et al., 1989). However, this method encounters problems if the discharge is variable from one trial to the next. Because the cat's attention was changing considerably throughout the recording session, there was some trial-totrial covariation in the neuron firing rate. We therefore chose to use instead the second alternative i.e., to estimate the instantaneous discharge probability directly from the spike train (Abeles, 1982; Palm et al., 1988). These instantaneous discharge probability estimates were used to calculate the expected correlation on a single-trial basis. Single-trial expectations were then summed to obtain the expected correlation caused by firing rate covariation. The assumptions made to estimate the instantaneous firing rate are then critical for the interpretation of results. Because we analyzed the spike train correlation during a period without any sudden change in the stimulus presentation, we expect the instantaneous firing rate to vary smoothly during this time. Therefore, we used a simple Gaussian kernel estimator to assess the instantaneous discharge probability. The spike train was simply filtered by convolution with a Gaussian function (SD, $10 \mathrm{msec}$; Fig. $1 F$; Silverman, 1986). This means that only synchrony that is more precise than the $10 \mathrm{msec} \mathrm{SD}$ of the Gaussian kernel used to estimate the instantaneous discharge probability will test as significant using our analysis.

$C C H$. Synchronization was quantified by means of the $\mathrm{CCH}$ (Fig. $2 A$ ). The $\mathrm{CCH}$ counts, when divided by the number of trigger spikes, represent the conditional probability of the occurrence of a response spike if a trigger spike occurred. When two spike trains are independent, the $\mathrm{CCH}$ is flat, i.e., the conditional probability remains constant whatever the time interval. If the $\mathrm{CCH}$ is not flat, there is some functional correlation between the cells (Perkel et al., 1967; Moore et al., 1970).

All analysis was performed on the $\mathrm{CCH}$ smoothed by means of a 5 msec window average, advanced in $1 \mathrm{msec}$ time steps. Significance was assessed assuming that the spike distribution in each window followed a Poisson distribution, using a threshold of $p<0.001$. The probability that the number of coincidences $c$ will be at least as many as the number observed, $C$, given that $E$ are expected, was calculated as Equation 1:

$$
P(c \geq C)=1-\sum_{i=0}^{i=C-1} \frac{e^{-E} E^{\mathrm{i}}}{\mathrm{i} !}
$$

This method for significance quantification is independent of the bin width, but still requires that the event probability is very small and independent from the occurrence of the other events (Poisson process).

To measure stimulus-locked changes in excess synchronization, we calculated the time-resolved $\mathrm{CCH}$. An example is displayed in Figure $5 C$. The abscissa $X$ corresponds to time relative to the stimulus movement onset, whereas the ordinate $Y$ is the lag time relative to each spike of cell 1. It is exactly as if the $\mathrm{CCH}$ was plotted in a gray scale as a function of peristimulus time, like in a raw JPSTH (Palm et al., 1988; Aertsen et al., 1989). For each trial, we calculated the time-resolved cross-correlation and its expectation function, using the instantaneous frequency estimate of the two cells. The time-resolved cross-correlation and its expected value were then summed across trials and compared ( $1 \mathrm{msec}$ bins). The $\mathrm{CCH}$ could be extracted from the time-resolved $\mathrm{CCH}$ by summing along the stimulus-related time axis $X$ (see Fig. $5 G$ ).

The peak width was determined from the $\mathrm{CCH}$ by the intersections of the observed and expected count curves. The high level of confidence used $(p<0.001)$ ensured that the detected peaks were visible to the naked eye and obviated the need for an additional criterion on the peak amplitude. The peak with the highest amplitude was called the "central peak" and was characterized by the relative modulation amplitude (RMA), calculated as the ratio of the peak amplitude to the expected value: (max - expect)/expect (Engel et al., 1990, 1991a,b,c; Brecht et al., 1999) and by the peak width at half-height. The RMA is related to the factor $k$, which is the ratio of maximum peak count to the expected count: max/expect (Sears and Stagg, 1976; Kirkwood and Sears, 1982). Hence,
$\mathrm{RMA}=(\max -$ expect $) /$ expect $=k-1$, which has also been described as the relative peak height (Cope et al., 1987).

If there was more than one central peak within $\pm 70 \mathrm{msec}$, the other significant peaks were called "satellite peaks" and were taken as evidence for an oscillatory correlation.

$\mathrm{CCH}$ shift predictors. When spikes are produced in response to a stimulus, the stimulus could synchronize the recorded cells. This stimulus-related synchronization was quantified by the shift predictor (Perkel et al., 1967; Palm et al., 1988). These predictors are computed similarly as for the $\mathrm{CCH}$ (Fig. $2 B$ ), except that the spike trains correlated are related to two successive trials (Fig. $2 C$ ). If the stimulus direction was varied (30 recordings), the shift predictor was computed with the next trial in the same direction. The expectation of the shift predictor was also calculated using the instantaneous discharge probability estimates, as explained for the time-resolved cross-correlation. Significant peaks in the shift predictor then indicated precise time locking of spikes to the stimulus presentation.

$A C H$. Autocorrelation histograms were also computed for each spike train (Fig. 2D), and the presence of satellite peaks was used to quantify whether the discharge was oscillatory (see Fig. $5 F, H$ ). Statistical requirements for significance were similar to the $\mathrm{CCH}$.

An ACH shift predictor (Fig. 2E) was computed between the $n$th and $(n+1)$ th trials. The expectation was calculated on a single-trial basis, using the instantaneous discharge probability, as explained for the timeresolved cross-correlation. Significant peaks in the ACH shift predictor indicated that spikes were time-locked to the stimulus.

$C E s$. If a central peak was observed in the $\mathrm{CCH}$, we used the number of significant bins of the smoothed histogram to define the time delay during which a spike occurring in both cells was called a CE. In the example of Figure 5, four windows centered at $-1,0,1$, and $2 \mathrm{msec}$ were significant, so that each time a spike of the second cell occurred between $1.5 \mathrm{msec}$ before and $2.5 \mathrm{msec}$ after a spike of cell one, it was considered as a $\mathrm{CE}$. The $\mathrm{CE}$ definition was thus directly related to the $\mathrm{CCH}$ peak, in contrast to previous definitions that have used an arbitrary allowed interval (Grün, 1996; Riehle et al., 1997). The moment of each CE was determined as the mean time between the two spikes: $\left(t_{1}-t_{2}\right) / 2$ (Pauluis and Baker, 2000). This definition allowed two CEs to occur by chance exactly at the same moment. If the two cells fired together in a short burst, the number of CEs would be the product of the number of spikes in each burst (Fig. $2 F$ ). This multiplicative property mirrors the way in which bursts of spikes contribute to the $\mathrm{CCH}$.

Once the CEs had been defined, it was possible to calculate their ACH and $\mathrm{ACH}$ shift predictor, which we will denote $\mathrm{CE}-\mathrm{ACH}$ and $\mathrm{CE}-\mathrm{ACH}$ shift predictor. This allowed the characterization of oscillations and stimulus time locking in the CEs.

Burst perturbation analyses. Many cells recorded in this study showed burst discharges. Spike bursts invalidated the Poisson assumption we made for statistical testing (Eq. 1). To asses the influence of this firing pattern on our results, we designed a control analysis. The bursts in spike trains, defined as a succession of ISIs $<3 \mathrm{msec}$, were located. This arbitrary value is convenient and comes from the definition of the chattering cells in the visual cortex (Gray and McCormick, 1996). The spikes of each burst were deleted and then added back to the spike train after a random shift (uniform distribution), which was the same for the spikes belonging to the same burst (Fig. $2 G$ ). Any spikes that originally fell within the new location of the burst were moved to the part of the spike train from which the burst had been removed. This technique ensured that the number of short ISIs was constant or even increased, whereas the precise timing of the spike bursts was destroyed. All measures were then recalculated to assess the impact of burst precision on our statistical procedures.

The same jittering method was applied to CE trains to test whether the time precision of CE bursts was relevant to our findings.

\section{RESULTS}

\section{Correlation histograms}

Of 686 pairs of spike trains tested for cross-correlation, 181 were selected as having a reasonable amount of data ( $>500$ spikes in each train and mean cross-correlation count per bin $>15$ ). A significant central peak in the $\mathrm{CCH}$ was found in 125 recordings (Table 1). Fourteen of one hundred twenty-five (14 of 125) CCHs involved the activity of two single units, and the others were from multiunit activities (39 of 125 involved a single and a multiunit 
A

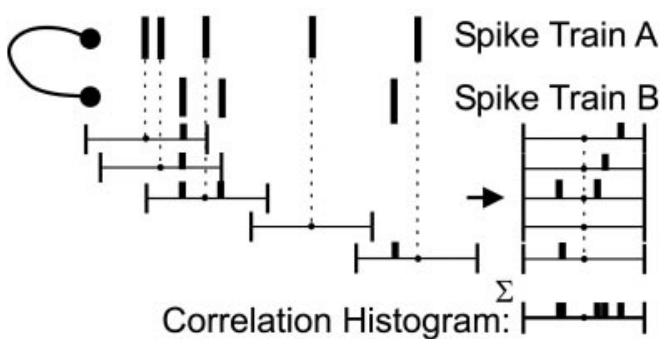

B Cross-Correlation Histogram

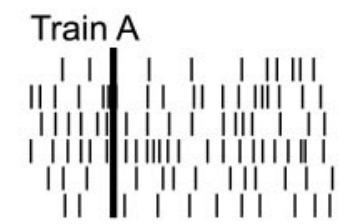

C
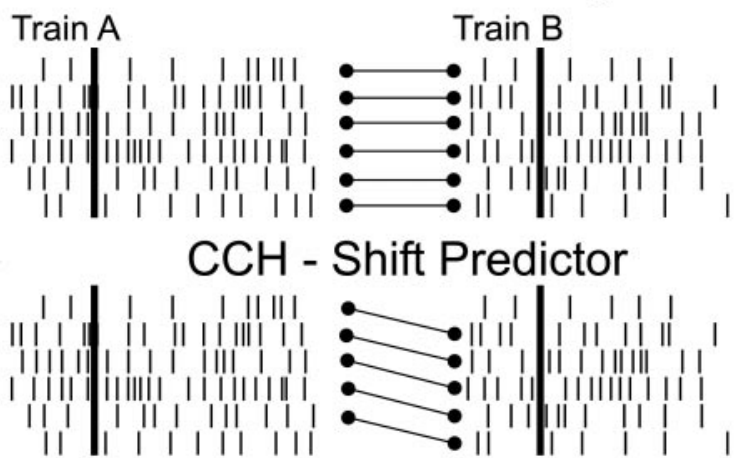

D Auto-Correlation Histogram

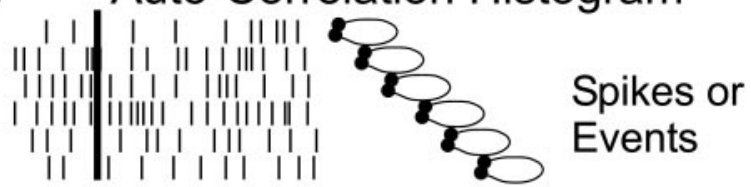

E

$\mathrm{ACH}$ - Shift Predictor

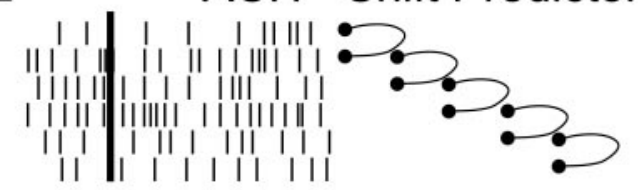

$\mathrm{F}$

CE Multiplication

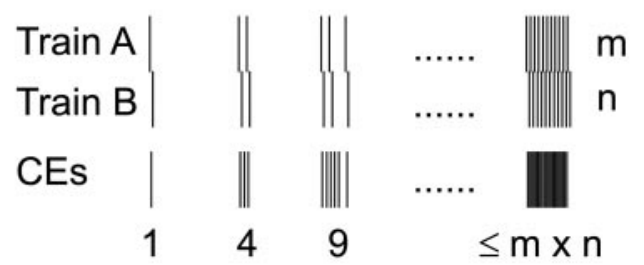

G

Burst Jittering Method

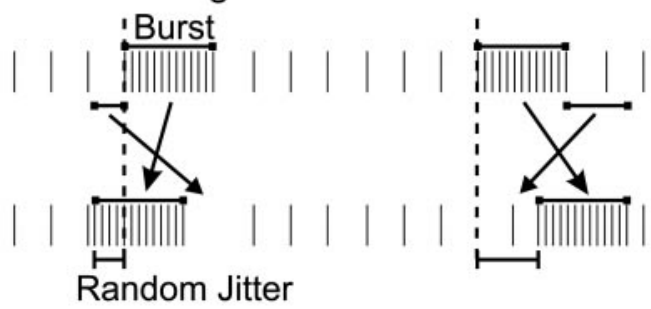

Figure 2. The counting process involved in the $\mathrm{CCH}$ and related measures. $A$, For each spike of the train $\mathrm{A}$, spikes of train $\mathrm{B}$ occurring within a fixed window relative to the spike of A cause the corresponding bins of the $\mathrm{CCH}$ to be incremented. The sum of all these windows gives the $\mathrm{CCH}$. $B$, Correlation is calculated from two spikes train of the same trial. $C$, Conversely, the $\mathrm{CCH}$ shift predictor is calculated between the $n$th trial of A
Table 1. Quantitative results

Number of recordings

\# Pairs
\# CCH with $>500$ spikes \& offset $>15$
\# Pairs with $\mathrm{CCH}$ peak
\# CCH with significant satellite peak (s)
\# CCH with significant trough(s)
\# Trains with $>500$ spikes
\# ACH peaks $\leq 8 \mathrm{msec}$
\# ACH peaks $>8 \mathrm{msec}$
\# CCH-SP offset $>15$ :
\# Significant CCH-SP
\# Significant ACH-SP
\# CE-ACH-SP offset $>15$ :
\# CE-ACH-SP with central peak
\# ACH-CE with satellite peaks

686

181

125

16

68

435

17

40

123

1

8

63

47

42

The main results for pooled recordings are detailed in this table. The number of pairs considered was 686 . Only 181 recordings were obtained from trains of $>500$ spikes each and exhibiting mean $\mathrm{CCH}$ level larger than 15 spikes per window. The number of pairs with significant $\mathrm{CCH}$ peak is then given, with the number of pairs having significant satellite peaks and troughs. There were 435 trains that exhibited $>500$ spikes. The number of satellite peaks in $\mathrm{ACH}$ are presented separately with the assumption that a peak at $\leq 8 \mathrm{msec}$ means that the cells could be bursting and that a longer delay means an oscillatory discharge (Fig. 3D). As shown in the second part, only eight trains showed a discharge that was time-locked to the stimulus presentation. In only one $\mathrm{CCH}$, the central peak could be related to this time locking. In contrast, the CEs seemed strongly time-locked to the stimulus presentation, and they exhibited satellite peaks very often.

activity, and 72 of 125 involved two multiunit activities). Only three $\mathrm{CCHs}$ were obtained from cells recorded with the same electrode. In the selected set of recordings with sufficient data ( $n=362=2 \times 181$ trains), the proportion of recordings that had $>25 \%$ of their ISIs shorter than 3 msec was $32.6 \%$ ("bursting trains"). This proportion was not significantly different in units that were part of a pair showing a $\mathrm{CCH}$ peak $(34.0 \%$; $n=250$; binomial test). In these data, we conclude that bursts do not predispose to significant $\mathrm{CCH}$ central peaks.

The properties of the significant $\mathrm{CCH}$ central peaks are described in Figure 3. The RMA is plotted in Figure $3 A$. Except in few cases, the RMA was $>0.1$, which has been used previously as a significance threshold (Engel et al., 1990).

The distribution of the central peak time lag is shown in Figure $3 B$ and is well centered on 0 msec. Figure $3 C$ displays the distribution of the width at half height for the central peak. Peaks were narrow, corresponding to the "Tower" type of Nelson et al., (1992): as noted in Materials and Methods, our analysis technique was specifically designed to detect such narrow peaks. Only 16 recordings showed significant satellite peaks at nonzero lag (Fig. 3D, dark gray).

Shift predictors were constructed by cross-correlating one spike train recorded during a given trial with the other spike train recorded during the next trial (Perkel et al., 1967). The use of an instantaneous discharge probability estimate allowed direct significance quantification for the shift predictors. Only one of the

$\leftarrow$

and the $(n+1)$ th trial of B. $D$, To calculate an $\mathrm{ACH}$, the same train is used twice. $E$, Again, the ACH shift predictor involves the $n$th trial and the $(n+1)$ th trial, both related to the same cell. $F$, When two spikes occur within a time delay corresponding to the $\mathrm{CCH}$ central peak, they are termed a CE. This definition also assumes that the maximum number of CEs within this time window is the product of the number of spikes. $G$, During burst jittering, the whole burst is shifted with a random delay, and the spikes that are at the target location are swapped with the original burst. 
A

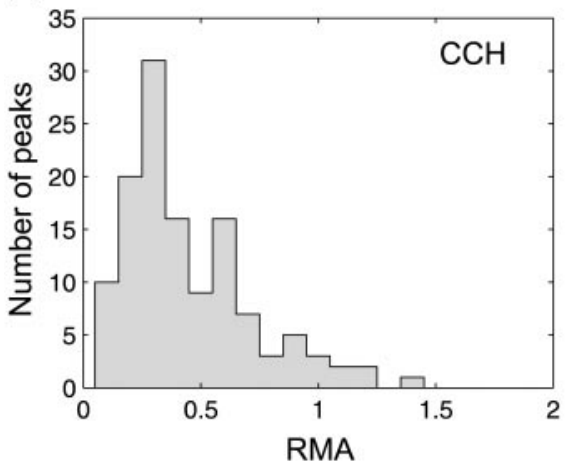

\section{$\mathrm{C}$}

Figure 3. $\mathrm{CCH}$. After filtering, the central peaks in $\mathrm{CCH}$ s were quantified by their RMA: (max expect.)/expect. The RMA distribution is shown in $A$. $B$, The peak lag distribution is precisely centered on $0 \mathrm{msec}$ (mean, $0.02 \pm 1.19 \mathrm{msec} \mathrm{SD} ; n=$ $125)$, and the peak width at half height is shown in $C$ to be centered on $5 \mathrm{msec}$. $D$, Satellite peaks were identified in ACHs, and their delay distribution is shown in light gray. Some satellite peaks were also found in the CCHs and are displayed in dark gray. Most such peaks were found between 12 and 18 msec $(55-85 \mathrm{~Hz})$, but they represented $<15 \%$ of the recordings (Table 1$)$.
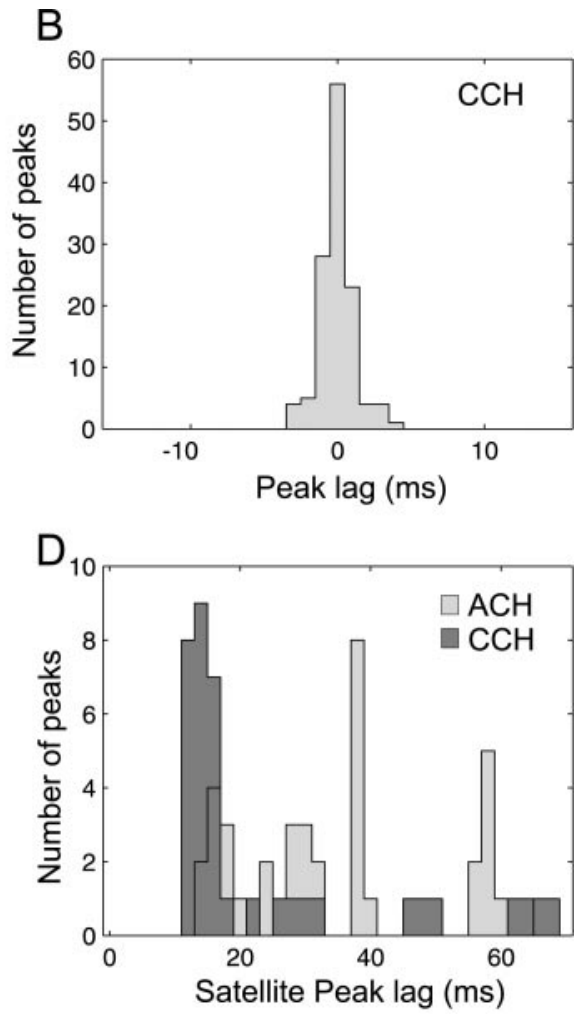

$\mathrm{CCH}$ shift predictors showed significant features, in contrast to the preponderance of central peaks in the CCHs. This indicates that only one of the $\mathrm{CCH}$ central peaks could be attributable to spike time locking to the stimulus presentation.

Examples of ACHs are shown in Figure 5, $F$ and $H$. Among trains with $>500$ spikes $(n=435)$, a significant peak within 8 msec of zero lag in the ACH was found in 17 recordings (Table 1); we interpreted these peaks as indicating a stereotyped burst discharge.

Satellite peaks in ACHs at $>8$ msec lag were found in 40 of 435 trains (see Fig. $5 F$ ). Figure $3 D$ shows the distribution of their time lags in light gray; this has a first mode centered on $16 \mathrm{msec}$ (63 $\mathrm{Hz}$ ), and some others at 30 and $40 \mathrm{msec}$. A similar distribution was found for the $\mathrm{CCH}$ satellite peaks (dark gray, 16 recordings). Only eight spike trains exhibited a significant peak in the $\mathrm{ACH}$ shift predictor (Table 1), illustrating that these cells had a discharge that could be time-locked to the stimulus presentation.

Although oscillatory synchronization as assessed from the presence of satellite peaks was rare, $>50 \%$ (68 of 125) of the $\mathrm{CCH}$ central peaks were flanked by one or two significant troughs. In these 68 recordings, it is possible that correlated spike trains with a narrow central peak would have produced a smoothed central can also be summed along the $y$-axis between -1.5 and $+2.5 \mathrm{msec}$ to give the CE count shown in $D$ (dark gray). The expected CE count is calculated similarly and shown in light gray. The significant peaks are marked by a star ( $p<0.005$ in a 9 msec window). The ACHs for each spike train are shown in $F$ and $H$. The central bin is set to the value of the adjacent ones. In $E$, the significance test of the CE count is plotted as a surprise test: $\log _{10((1-P) / P)}$. Each time the $p$ values pass below 0.005 , the curve is shaded in dark gray, and the corresponding point in $D$ is marked by a star. Same experiment as in Figure 1.peak in the expected $\mathrm{CCH}$ calculated from the instantaneous firing rates, leading to the erroneous detection of troughs in the difference. However, if we modified the instanta- neous discharge estimate by extending the Gaussian kernel from 10 to $150 \mathrm{msec} \mathrm{SD}$, we still obtained 64 recordings with significant troughs, making it unlikely that the troughs were artifactually generated in this way.

We could not detect any effect of the stimulus velocity on cellular synchronization; Figure 4 provides a summary for the 13 pairs on which this was tested. With increasing velocity, the maximum firing rate increased slightly, but this did not reach significance (mean difference, 18.4 spikes/sec $\pm 13.1 \mathrm{SE} ; p=0.08$; paired $t$ test). Raw CCHs computed for lower velocities (5-35\% sec) are displayed in the left column, and those for higher velocities are displayed in the right $(15-70 \% \mathrm{sec})$. Visual inspection reveals that the peak shapes were remarkably constant irrespective of the stimulation velocity. There was no consistent trend in synchrony strength with stimulus velocity, as measured by the RMA (displayed on the right side of each $\mathrm{CCH}$ ). There was a slight tendency for an increase in synchronous oscillations at the high velocity: a significant $(p<0.001)$ satellite peak appeared in one data set (large arrowhead), and also in three others if the significance level was relaxed to $p<0.0025$ (small arrows).

\section{Coincident event analyses Coincident event distribution}

The following analyses were performed to assess the distribution of CEs in the poststimulus time average to shed light on their origin (Fig. $5 D, E$ ). Figure $5 B$ shows the response of two cells during the presentation of a moving stimulus (Fig. $5 G$ ). The corresponding ACHs are shown in Figure 5, $F$ and $H$.

The time-resolved cross-correlation histogram is displayed in Figure 5C. After testing for significance and filtering (twodimensional Gaussian convolution $2 \mathrm{msec}$ SD), significant regions $(p<0.01)$ were highlighted by a white line. From $\sim 130-250$ msec, the dark spots on the zero-lag axis are surrounded by two brighter traces, resembling eraser marks, which denote troughs 

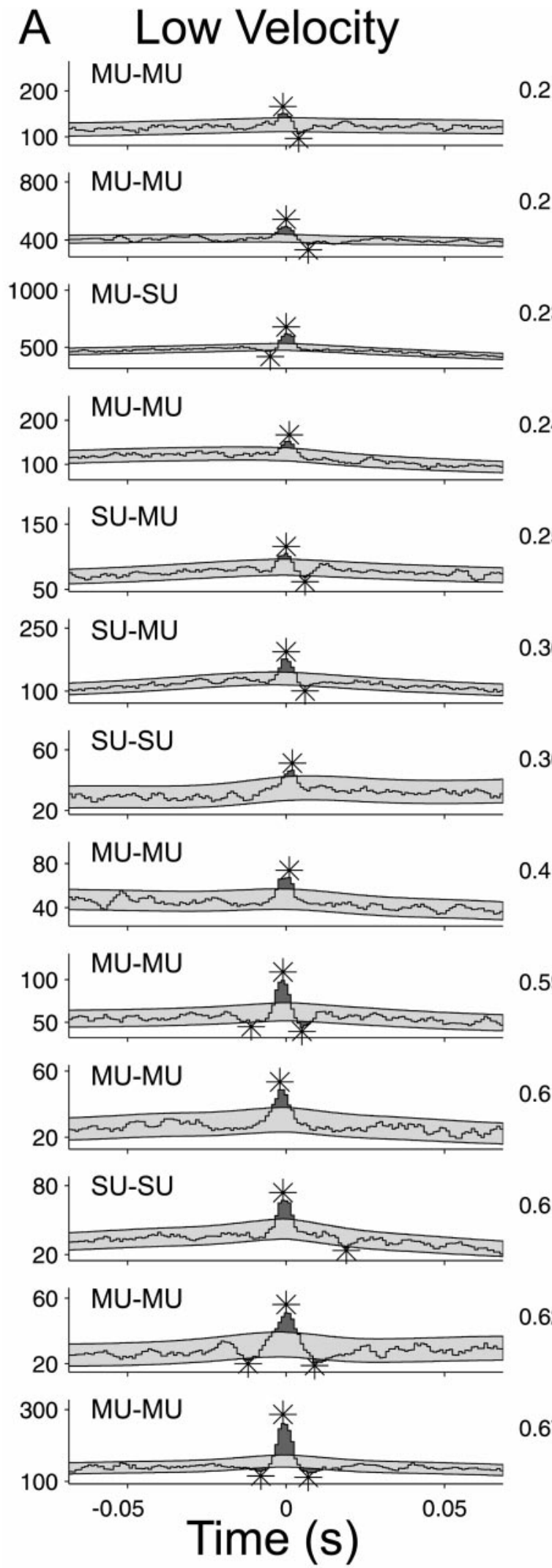
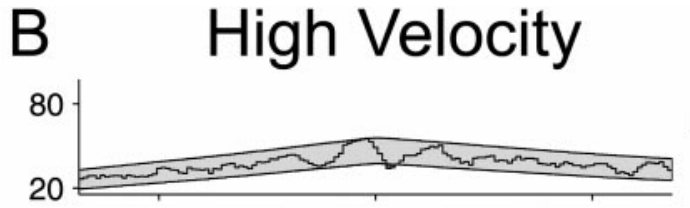

n.s.

350
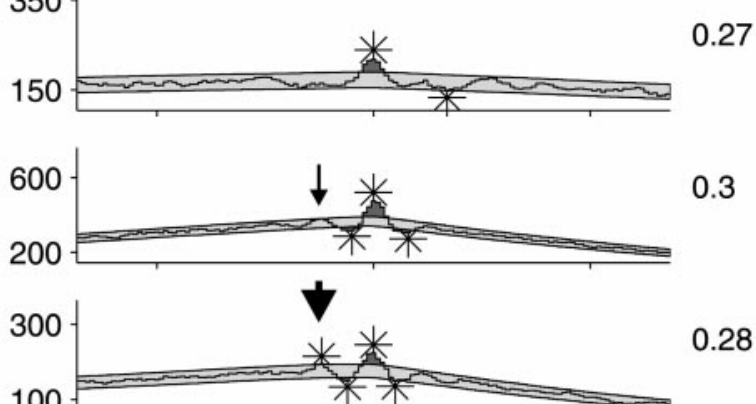

0.25
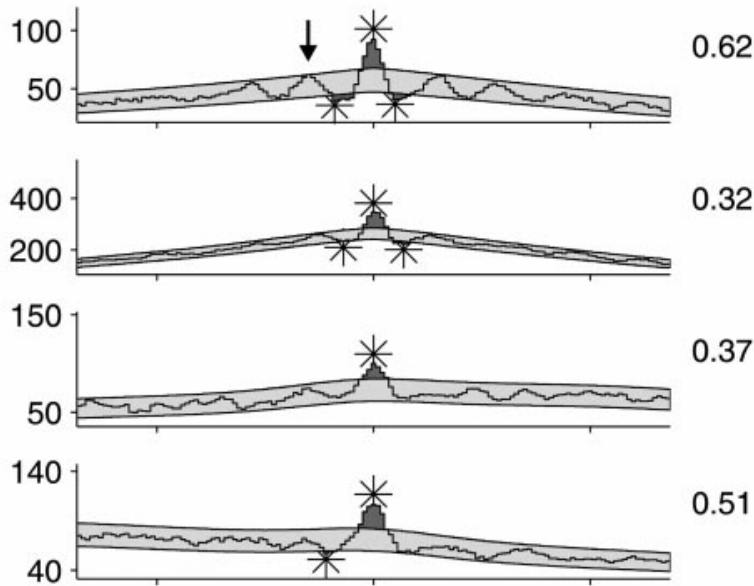

0.59

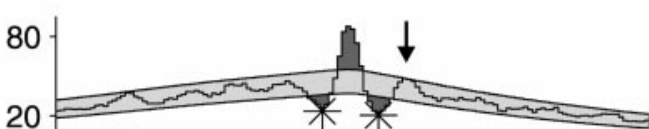

0.91

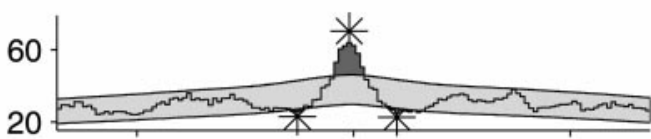

0.71
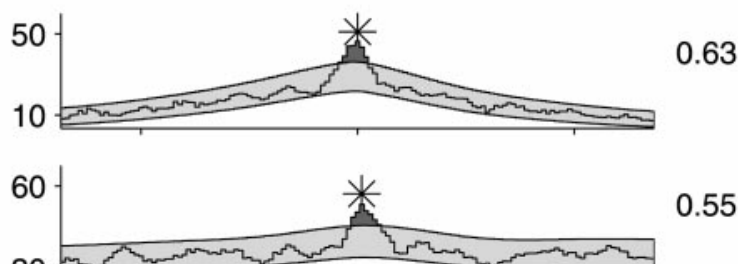

0.67

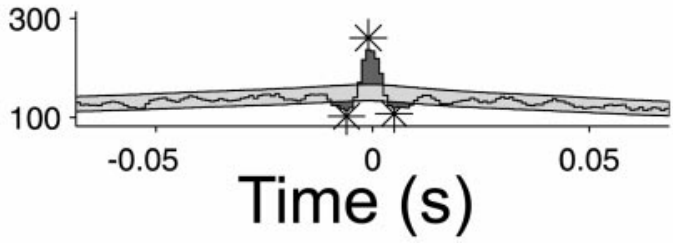

Figure 4. Stimulus velocity testing. Thirteen pairs were tested for low $\left(A, 5-35^{\circ} / \mathrm{sec}\right)$ and high $(B, 15-70 \%$ sec $)$ stimulus velocities, and the resulting CCHs were compared. Smoothed CCHs are shown for every set of data, and the expected $\mathrm{CCH} \pm 3$ SD has been shaded in light gray ( $p<0.001 ; \sqrt{ }$ count). Stars denote significant peaks and troughs. The RMA is indicated in the top right corner of each CCH. Nine of 13 peaks increased their RMA when the stimulus velocity increased. The $\mathrm{CCH}$ shift predictors were flat in all cases. 


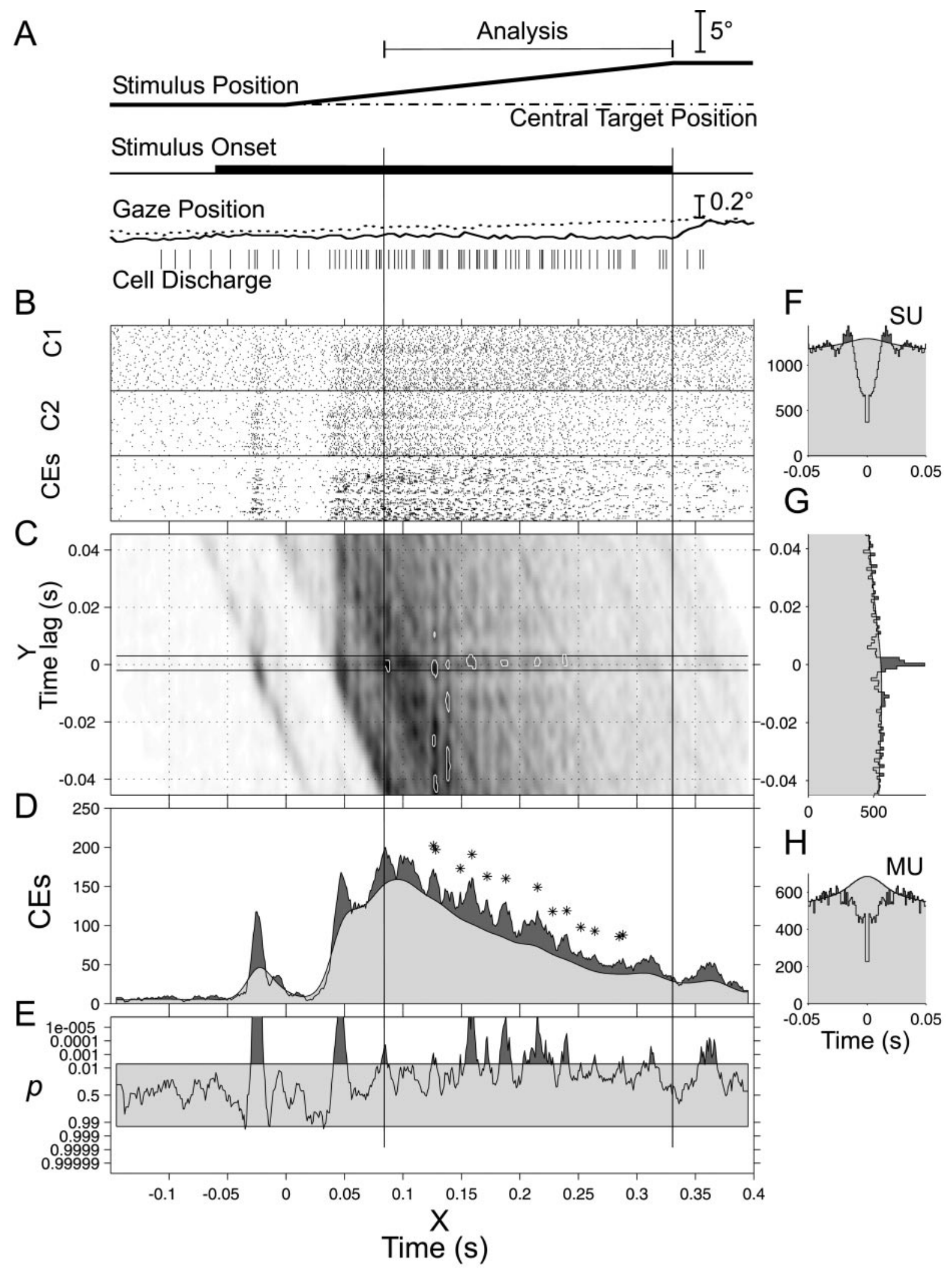

Figure 5. Time-resolved cross-correlation. $A$, Schematic representation of stimulus time course, along with the gaze position and spike train of the single trial shown in Figure 1E. B, After off-line discrimination, action potentials were plotted in the two top rasters. Their cross-correlation is shown in $G$, and the delay defining a CE was determined from the significant bins of the central peak $(-1.5$ to $+2.5 \mathrm{msec})$. The CEs were displayed in the third raster of $B$. The texture is more contrasted in the CE raster than in the spike rasters because $\mathrm{CE}$ calculation enhances burst coincidences. $C$, The smoothed time-resolved cross-correlation is shown on a gray scale. The CEs are shown inside the two horizontal lines. The expected value of the time-resolved cross-correlation was calculated from the instantaneous discharge probabilities for each trial and then summed. The first percentile of most significant $p$ after filtering is highlighted by the white curves. The $\mathrm{CCH}(G)$ was calculated as the bin sum along the abscissa between 80 and $333 \mathrm{msec}$ (vertical lines). The time-resolved cross-correlation 
A
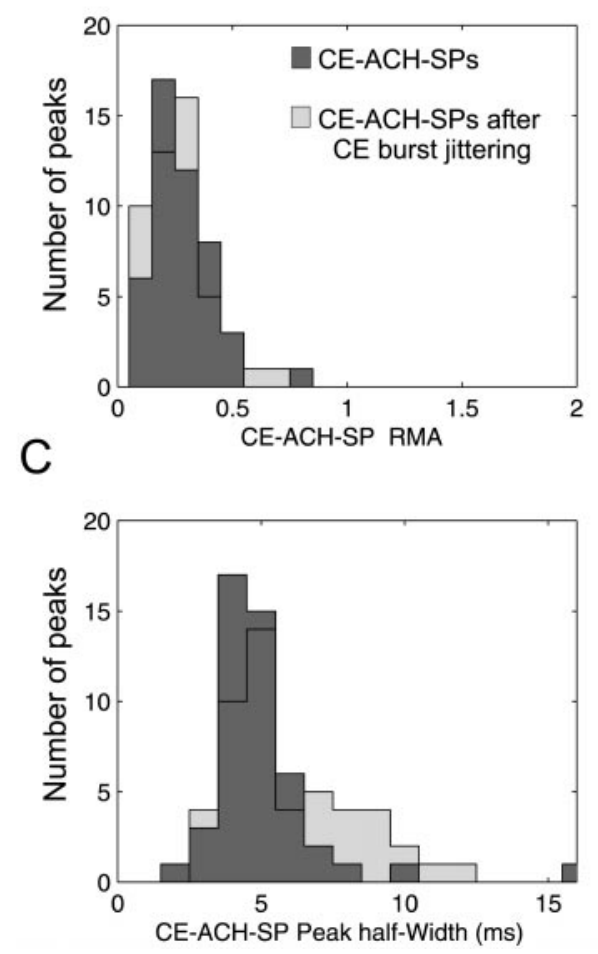

B
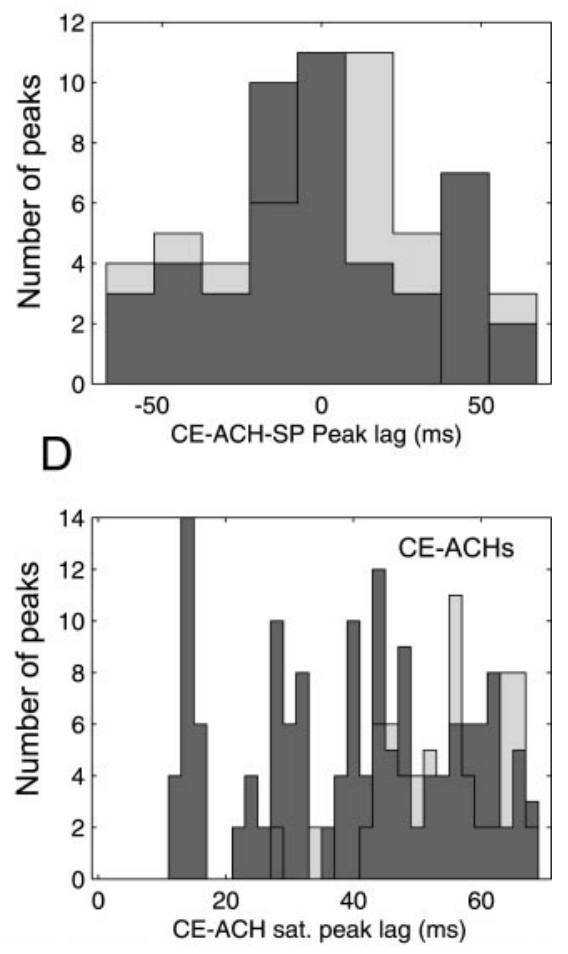

Figure 6. $\mathrm{CE}-\mathrm{ACH}$ shift predictor and $\mathrm{CE}-\mathrm{ACH}$. CEs were found to be time-locked to the stimulus presentation in 47 recordings (dark gray). The background light gray histograms refer to the results obtained after CE burst jittering (see Results). $A$, Peaks did not have a large amplitude. $B$, Peak lag distribution was broadly centered on 0 $\operatorname{msec}(-0.9 \mathrm{msec} \pm 32.3 \mathrm{SD} ; n=47)$. $C$, The peak width at half height was similar to that for $\mathrm{CCH}$ peaks. $D$, Autocorrelation performed on CEs revealed more satellite peaks than any other correlation measure, with a mode of $\sim 15$, and then possibly at 30 and $45 \mathrm{msec}$. either side of the central peak in the $\mathrm{CCH}$. The raw $\mathrm{CCH}$ is plotted in Figure $5 G$ and corresponds to the sum of the timeresolved cross-correlation along the stimulus time axis, between 80 and $333 \mathrm{msec}$. The $\mathrm{CCH}$ expectation (calculated from the instantaneous firing rates) is superimposed in light gray. The number of adjacent significant windows in the $\mathrm{CCH}$ is shown by the two horizontal lines on both sides of $0 \mathrm{msec}$ lag in the time-resolved cross-correlation histogram (bins, -1 to $+2 \mathrm{msec}$; Fig. 5C). All the points between these two lines were called CEs. Such events were summed and plotted in Figure $5 B$ as rasters (CEs) and in Figure 5D as a PSTH (dark gray curve), on which is superposed the corresponding expectation (light gray). The coincidence count (Fig. 5D) was then tested to quantify $\mathrm{CE}$ excess significance, assuming that the CEs follow a nonstationary Poisson distribution with rate equal to the sum of the single-trial CE expectations (compare Eq. 1). Significant excess in a particular time window during the period of $80-333 \mathrm{msec}$ is indicated on Figure $5 D$ by a star. Significance is plotted as a surprise measure (cf. Aertsen et al., 1989) in Figure 5E.

Such an analysis shows when CEs were present in excess during the poststimulus time. To address the issue of the distribution of CEs across time and to show how the CE density could vary from trial to trial, we computed the $\mathrm{CE}-\mathrm{ACH}$ shift predictor for the complete set of trials in each of the 125 experiments with a significant $\mathrm{CCH}$ peak. Peaks in the $\mathrm{CE}-\mathrm{ACH}$ shift predictor indicate that the CEs tended to occur at similar times after the stimulus from one trial to the next. Forty-seven recordings exhibited peaks in both the $\mathrm{CCH}$ and the $\mathrm{CE}-\mathrm{ACH}$ shift predictor, suggesting that CEs could be stimulus locked in this way. This is in contrast to the fact that only one $\mathrm{CCH}$ shift predictor and only eight ACH shift predictors were peaked (Table 1).

Figure 6 shows the results of correlation analysis performed on CEs. The distribution of the RMA of the significant central peak of the $\mathrm{CE}-\mathrm{ACH}$ shift predictor is shown in Figure $6 A$. The peak lag distribution is shown in Figure $6 B$. The peak lag of the $\mathrm{CE}-\mathrm{ACH}$ shift predictor was broadly centered on $0 \mathrm{msec}$. The width of $\mathrm{CE}-\mathrm{ACH}$ shift predictor peaks had a similar distribution to the width of peaks in the $\mathrm{CCH}$ (Figs. 3C, 6C). Finally, we performed autocorrelation analysis on CEs, and satellite peaks were found at $\sim 15$ and 30 (Fig. $6 D$ ), as for spike train autocorrelation (Fig. 3D; $42 \mathrm{CE}-\mathrm{ACHs}$ vs 55 cells).

\section{Effect of burst discharge on statistical measures}

Fifty percent of the recordings with a significant peak in the $\mathrm{CE}-\mathrm{ACH}$ shift predictor were from bursting trains $(>25 \%$ ISIs shorter than $3 \mathrm{msec} ; n=94)$, and $32.6 \%$ of pairs with peaked $\mathrm{CCH}$ came from bursting trains; these proportions were significantly different ( $p<0.001$, binomial test). The statistical tests used to detect peaks assumed that spike trains could be approximated by Poisson processes, an assumption clearly violated when

can also be summed along the $y$-axis between -1.5 and $+2.5 \mathrm{msec}$ to give the CE count shown in $D$ (dark gray). The expected CE count is calculated similarly and shown in light gray. The significant peaks are marked by a star $(p<0.005$ in a 9 msec window). The ACHs for each spike train are shown in $F$ and $H$. The central bin is set to the value of the adjacent ones. In $E$, the significance test of the CE count is plotted as a surprise test: $\left.\log _{10((I-P) / P}\right)$. Each time the $p$ values pass below 0.005 , the curve is shaded in dark gray, and the corresponding point in $D$ is marked by a star. Same experiment as in Figure 1.can also be summed along the $y$-axis between -1.5 and $+2.5 \mathrm{msec}$ to give the CE count shown in $D$ (dark gray). The expected CE count is calculated similarly and shown in light gray. The significant peaks are marked by a star ( $p<0.005$ in a 9 msec window). The ACHs for each spike train are shown in $F$ and $H$. The central bin is set to the value of the adjacent ones. In $E$, the significance test of the CE count is plotted as a surprise test: $\log _{10((1-P) / P}$. Each time the $p$ values pass below 0.005 , the curve is shaded in dark gray, and the corresponding point in $D$ is marked by a star. Same experiment as in Figure 1. 


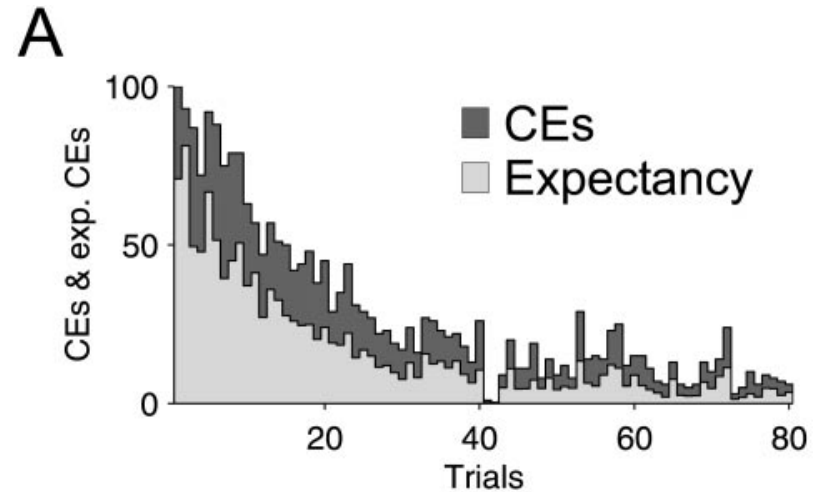

B

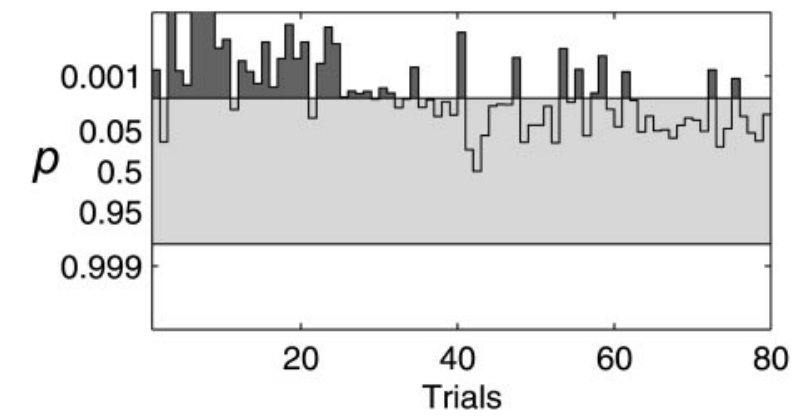

C

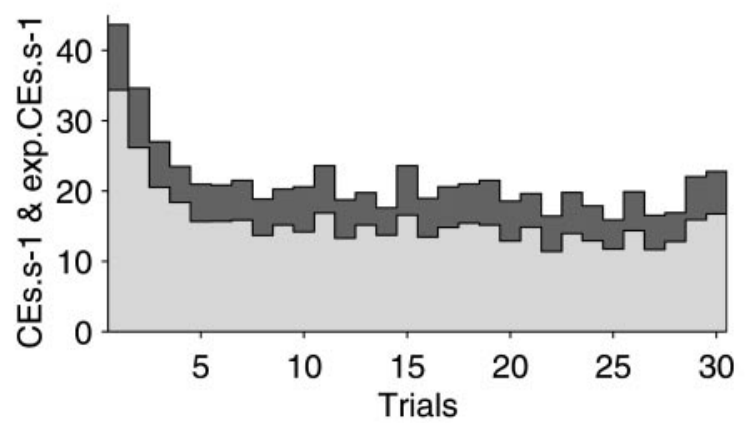

Figure 7. Trial repetition. Instantaneous discharge probability estimates allow quantification of the $\mathrm{CE}$ excess on a single-trial basis. $A, \mathrm{CE}$ (dark gray) and expected CE count (light gray) are shown for all trials. $B$, The surprise test on each trial was positive more often during the first part of the experiment than during the second one. $C$, CE count and expectation were averaged for all 81 data sets, presenting at least one $\mathrm{CCH}$ peak and composed of 31-40 trials. On average, the decrease in CE expectation occurred within the first five trials. This contrasts with $A$, but this experiment in $A$ was the first of the day, and attention could have been longer sustained.

bursts are present. We therefore tested whether the results obtained above could have been influenced by the presence of bursts in the spike trains. Rather than attempt to generate a more appropriate theoretical statistical model for the spike trains, we used the empirical burst-jittering analysis described in Materials and Methods (Fig. 2G), in which whole bursts were randomly swapped with other nearby segments of the original spike train. This was designed to destroy precise burst synchronization between the two simultaneously recorded neurons, while maintaining the bursting nature of the individual spike trains.

When jittering was applied to bursts in the original spike trains, of $125 \mathrm{CCHs}$ with significant peaks, only 62 remained significant after the application of a random jitter with maximum size \pm 10 msec. This number remained fairly constant for larger jitters up to $\pm 50 \mathrm{msec}$. We can therefore be confident that at least half of the $\mathrm{CCH}$ central peaks were caused by burst synchronization and were not an artifact of cell bursting.

A contrasting result was obtained when burst jittering was applied to the $\mathrm{CE}$ trains. Of 63 recordings suitable for $\mathrm{CE}$ analysis, between 46 and 51 showed significant $\mathrm{CE}-\mathrm{ACH}$ shift predictors for jitters from \pm 1 to $\pm 50 \mathrm{msec}$; this compared with 47 significantly peaked $\mathrm{CE}-\mathrm{ACH}$ shift predictors in the original data. The number of significant peaks was thus essentially unaffected by the burst jittering. Measurements made from these peaks, for the largest jitter tested $( \pm 50 \mathrm{msec})$, are shown in light gray in Figure 6. Surprisingly, the distribution of most of the measures was also qualitatively unaffected, even by this considerable jittering of the bursts. Peaks were no larger (Fig. 6A), similarly timed (Fig. 6B), and of comparable width (Fig. 6C). The only difference was that the jittered $\mathrm{CE}$ trains did not show an oscillatory peak in the $\mathrm{ACH}$ (Fig. 6D; no isolated peak at $16 \mathrm{msec} \mathrm{lag}$ ).

We conclude that the presence of peaks in many of the CCHs results from genuine short-term synchronization of bursting spike trains and is not solely a statistical artifact caused by the presence of bursts. However, the apparent precise time locking of CEs to the stimulus, as indicated by the presence of features in the $\mathrm{CE}-\mathrm{ACH}$ shift predictors, is by contrast likely to result from an artifactual influence of CE bursts on the statistical calculations.

\section{Single-trial analysis}

An important advantage of our method based on the instantaneous discharge rate is that it allows inspection and significance assessment of single trials, provided that enough spikes were collected. This is accordingly examined below.

Figure 7 illustrates how the CE count varied with trial repetition in a single recording session. This experiment was the first one of the day, so attention was probably sustained for an especially long time at the beginning of the session. There were 80 trials, each 333-msec-long; these are plotted sequentially along the abscissa in Figure $7 A$. The observed number of CEs is described by the dark gray histogram and the expected CE count by the overlying light gray area. Cells discharged at much higher rates during the first trials, which produced the higher expected $\mathrm{CE}$ count at that time. However, a clear CE excess persisted throughout.

The surprise test for each trial is presented in Figure $7 B$. CE excess failed consistently to test as significant for the later trials, because of the low number of counts expected reducing the power of the statistical tests.

$\mathrm{CE}$ rates from recordings with a significant cross-correlation peak were averaged for each trial. Figure $7 C$ shows this average for 81 experiments composed of 30-40 trials and that were recorded at different moments of different days (average trial duration, $1 \mathrm{sec}$ ). This confirms the results of the single cell pair shown in Figure 7, $A$ and $B$. Cells are usually more responsive during the first five trials; however, the $\mathrm{CE}$ excess remained significant $\left(p<10^{-9}\right)$ and fairly constant during the whole recording session.

\section{DISCUSSION}

\section{Methodological considerations}

The method developed in the present study offers many advantages over the usual JPSTH method (Aertsen et al., 1989). First, it is able to cope with highly nonstationary data because the $\mathrm{CE}$ estimate is adjusted for each trial separately and, in each trial, for 
every moment with the requested precision (here $10 \mathrm{msec}$ SD). Nearly every trial can be included securely in the rasters, even if cell firing rates are much lower or much higher than in the other trials. Such trials with covariant and unexplained discharge variations are pernicious when included in JPSTH because they are not described adequately by the PSTH and consequently bias the $\mathrm{CE}$ expectation. This leads to the assessment of large crosscorrelation peaks caused by patterns of covariant activities (Brody, 1999a,b; Pauluis and Baker, 2000). A way to control for this problem is to show that the expected $\mathrm{CCH}$ offset fits well the observed $\mathrm{CCH}$ offset for the each period of the experiment. This simple check is not performed in some CE analysis (Riehle et al., 1997). The method used here is based on the calculation of the CE expectation for each single trial and compensates very simply for this kind of problem. Second, it offers a quantitative approach to test significance of any correlation measure, including the shift predictors. Their significance was quantified previously by recursion or by comparison with the shuffled predictor. Third, when this method is coupled to traditional perturbation methods like burst jittering, it enables direct quantification of the spike or burst precision. Fourth, it allows trial by trial CE significance calculation, an ability that permitted the quantification of the effect of trial repetition and of which more sophisticated experimental paradigms could make use.

\section{Precise burst synchrony in the superior colliculus}

One of the main results of the present study is the direct evidence for precise burst synchrony in the visual response of collicular cells of the awake cat. Lisman (1997) suggested that in some regions, single spikes are just noise. It has been shown recently by Livingstone et al. (1996) that in the primary visual cortex of alert monkeys only bursts provided a clear indicator of the presence of a visual stimulus. Burst discharges in the SC have been reported previously by Mandl (1993) in the pretrigeminal cat during moving visual stimulus presentation, and $25 \%$ of the responding cells exhibited a $60-80 \mathrm{~Hz}$ burst frequency. We were able to show that such cells synchronize their short spike bursts with a precision of few milliseconds.

In contrast, Brecht et al. (1996, 1998, 1999) reported previously that synchrony takes place in the SC of the anesthetized cat with a wide time course: the mean width at half height was $51 \mathrm{msec}$ for corticotectal interactions, and similar values were found for intracollicular interactions $(>20 \mathrm{msec})$. However, Brecht et al. (1999) assessed CCH peaks by fitting a generalized Gabor function to the CCHs (König, 1994). Broad peaks could possibly be better identified than thin ones because curve fitting favors identification of large trends over narrow peak characterization, whereas our method assumes that wide peaks are caused by firing rate covariation.

In awake cats, the $\mathrm{CCH}$ peak width at half height was on average $5 \mathrm{msec}$ (Fig. $3 \mathrm{C}$ ). In awake animals in comparison to the anesthetized state, the temporal relationship changes from a coactivation pattern to precise synchrony, which is very interesting because the SC can be regarded as an attentive filter (Goldberg and Wurtz, 1972; Robinson and Kertzman, 1995; Kustov and Robinson, 1996) and because attentive tasks enhance synchrony in other brain areas (Murthy and Fetz, 1992, 1996a,b; Roelfsema et al., 1997).

Spike time locking has been described previously in response to a sudden change in the stimulus presentation (Mainen and Sejnowski, 1995). It has also been reported that most cells in the cat LGN and visual cortex could synchronize strongly on a $60 \mathrm{~Hz}$ monitor refresh rate (Wollman and Palmer, 1995). Such evident causes of fast stimulus locking are unlikely during our stimulus presentation because we used an oscilloscope with a position increment rate of $100 \mathrm{~Hz}$, and SC oscillations we found had a frequency of $65 \mathrm{~Hz}$. We also took care to start analysis after the fast transient because of the onset of the stimulus displacement and excluded the stimulus offset because such events would have locked the cell discharge. Although the synchrony between spikes is precise, they are not precisely time locked to the stimulus presentation.

It was shown recently that fixational eye movements can cause large response modification in the firing rate of visual cells in the primary cortex and lateral geniculate nucleus (Gur et al., 1997). Although the SC cells we recorded responded strongly to the visual stimulus, we cannot exclude that small eye movements were responsible for part of the synchronization.

\section{Oscillations in the superior colliculus}

We found some evidence of oscillation in the SC at $65 \mathrm{~Hz}$. According to previous simulation work (Traub et al., 1996; Pauluis et al., 1999), the oscillation frequency would depend on the physiology of local inhibitory interneurons. Lopez-Barneo and Llinas (1988) estimated the membrane time constant of neurons located in the stratum griseum intermediale of the SC in guinea pig to be $4.13 \pm 1.3(\mathrm{SE}) \mathrm{msec}(n=27)$, a value two times smaller than the shortest cortical membrane time constant (Koch et al., 1996). This could explain the fast oscillations in the SC. The involvement of inhibitory interneurons in network oscillations is also supported by the recent evidence showing inhibitory bursting cells in the intermediate and deep layers of the rabbit superior colliculus, which may form mutual inhibitory connections (Zhu and Lo, 2000).

There were 40 oscillatory ACHs, but many of the CCHs exhibited no satellite peaks (109 of 125). This would be interpreted, if the recordings had been made in the visual cortex, as a lock-in state (Eckhorn, 1994) that probably corresponds to suboptimal stimuli. Because of constraints on the duration of recordings in awake animals, and especially in cats, our stimulus parameters had to be rapidly adjusted to be close to, but probably did not reach, the optimal. Moreover, attention and motivation decreased during the experiment leading to a decrease in the response to the stimulus. Whereas attention modulates the visual response in the SC (Goldberg and Wurtz, 1972), it has been shown that stimulation of the mesencephalic reticular formation increases visually evoked oscillations in anesthetized and awake cat (Metherate et al., 1992; Munk et al., 1996; Steriade et al., 1996).

Another explanation for our failure to detect oscillations could be that although some occurred, their frequency was too irregular to be significant in the $\mathrm{CCH}$. This is supported by the fact that the $\mathrm{SC}$ receives both visual afferents from the retina, which have been shown to oscillate at $61-114 \mathrm{~Hz}$ in response to visual targets (Neuenswander and Singer, 1996; Castelo-Branco et al., 1998), and from the visual cortex in which moving stimuli induce typically 30-60 Hz oscillations (Gray et al., 1989; Singer and Gray, 1995; Castelo-Branco et al., 1998). Castelo-Branco et al. (1998) suggested that in response to moving stimuli, subcortical (LGN) and cortical oscillations dissociated, but if cortical mechanisms dominated, LGN responses could become phase locked to the cortical oscillations. Some SC cells could receive predominately retinal input, showing $65 \mathrm{~Hz}$ oscillations, whereas some others might receive both kinds equally. However, only a few satellite peaks were found to be compatible with the known cortical 
oscillation frequency, suggesting that in the main SC oscillations arise from a cortex-independent mechanism (Fig. 3D). Our results are in marked contrast to the low-frequency oscillations previously reported in the anesthetized cat $(5-20 \mathrm{~Hz}$; Brecht et al., 1999; Chabli et al., 2000).

\section{Trough-peak-trough pattern}

In our data, symmetrical troughs flanked many of the $\mathrm{CCH}$ peaks. Our previous modeling work has shown the conditions needed to reproduce this pattern (Pauluis, 2000). On the basis of this, we suggest that there are three different states of network dynamics that produce qualitatively different cross-correlation features. First, an isolated central peak is evidence for a common input, which may be either excitatory or inhibitory, and arise from either local or extrinsic circuits (Perkel et al., 1967). Where the central peak is flanked by troughs, this may reflect a common inhibitory feedback acting with delay on the recorded cells, possibly from the local interneurons (Pauluis, 2000). This is however one step short of full oscillatory network activity. Finally, there may be genuine oscillations, leading to satellite peaks in the crosscorrelation. Modeling work has shown the importance of mutual inhibition between interneurons to produce oscillatory activity (Wilson and Cowan, 1972; van Vreeswijk et al., 1994; Whittington et al., 1995; Traub et al., 1996; Wang and Buzsáki, 1996; White et al., 1998; Pauluis et al., 1999). The network state leading to a central peak flanked by troughs could therefore be an intermediate stage on the way to sustained oscillations. Our results should encourage experimenters to test the significance of satellite troughs to differentiate this pattern from an isolated central peak or a genuine oscillatory $\mathrm{CCH}$.

\section{REFERENCES}

Abeles M (1982) Quantification, smoothing, and confidence limits for single-units' histograms. J Neurosci Methods 5:317-325.

Abeles M (1991) Corticonics: neural circuits of the cerebral cortex. Cambridge, UK: Cambridge UP.

Aertsen AMHJ, Gerstein GL, Habib MK, Palm G (1989) Dynamics of neuronal firing correlation: modulation of "effective connectivity." J Neurophysiol 61:900-917.

Brecht M, Singer W, Engel AK (1996) Temporal coding in the cat superior colliculus. Soc Neurosci Abstr 22:1446.

Brecht M, Singer W, Engel AK (1998) Correlation analysis of corticotectal interactions in the cat visual system. J Neurophysiol 79:2394-2407.

Brecht M, Singer W, Engel AK (1999) Patterns of synchronization in the superior colliculus of anesthetized cats. J Neurosci 19:3567-3579.

Brody CD (1999a) Disambiguating different covariation types. Neural Comput 11:1527-1535.

Brody CD (1999b) Correlations without synchrony. Neural Comput 11:1537-1551.

Castelo-Branco M, Neuenschwander S, Singer W (1998) Synchronization of visual responses between cortex, lateral geniculate nucleus, and retina in the anesthetized cat. J Neurosci 18:6395-6410.

Chabli A, Guitton D, Fortin S, Molotchnikoff S (2000) Cross-correlated and oscillatory visual responses of superficial-layer and tecto-reticular neurones in the cat superior colliculus. Exp Brain Res 131:44-56.

Cope TC, Fetz EE, Matsumura M (1987) Cross-correlation assessment of synaptic strength of single Ia fibre connections with triceps surae motoneurones in cats. J Physiol (Lond) 390:161-188.

DeBusk BC, DeBruyn EJ, Snider RK, Kabara JF, Bonds AB (1997) Stimulus-dependent modulation of spike burst length in cat striate cortical cells. J Neurophysiol 78:199-213.

Eckhorn R (1994) Oscillatory and non-oscillatory synchronizations in the visual cortex and their possible roles in associations of visual features. Prog Brain Res 102:405-426.

Eggermont JJ (1990) The correlative brain. Theory and experiment in neural interaction. Berlin: Springer.

Engel AK, König P, Gray CM, Singer W (1990) Stimulus-dependent neuronal oscillation in cat visual cortex: Inter-columnar interaction as determined by cross-correlation analysis. Eur J Neurosci 2:588-606.

Engel AK, König P, Kreiter AK, Singer W (1991a) Interhemispheric synchronization of oscillatory neuronal responses in cat visual cortex. Science 252:1177-1179.
Engel AK, König P, Singer W (1991b) Direct physiological evidence for scene segmentation by temporal coding. Proc Natl Acad USA 88:9136-9140.

Engel AK, Kreiter AK, König P, Singer W (1991c) Synchronization of oscillatory neuronal responses between striate and extrastriate visual cortical areas of the cat. Proc Natl Acad Sci USA 88:6048-6052.

Goldberg ME, Wurtz RH (1972) Activity of superior colliculus in behaving monkey. II. Effect of attention on neuronal responses. J Neurophysiol 15:560-574.

Grantyn R (1988) Gaze control through superior colliculus: structure and function. In: Neuroanatomy of the oculomotor system (BüttnerEnnever, ed), pp 273-333. New York: Elsevier.

Gray CM, König P, Engel AK, Singer W (1989) Oscillatory responses in cat visual cortex exhibit inter-columnar synchronization which reflects global stimulus properties. Nature 338:334-337.

Gray CM, McCormick DA (1996) Chattering cells: superficial pyramidal neurons contributing to the generation of synchronous oscillations in the visual cortex. Science 274:109-113.

Griffith JS, Horn G (1963) Functional coupling between cells in the visual cortex of the unrestrained cat. Nature 199:893-895.

Grün S (1996) Unitary joint-events in multiple-neuron spiking activity. Thun, Frankfurt am Main: Harri Deutsch.

Gur M, Beylin A, Snodderly DM (1997) Response variability of neurons in primary visual cortex (V1) of alert monkeys. J Neurosci 17:2914-2920.

Hopfield JJ (1995) Pattern recognition computation using action potential timing for stimulus representation. Nature 376:33-36.

Hopfield JJ (1996) Transforming neural computations and representing time. Proc Natl Acad Sci USA 93:15440-15444.

Kirkwood PA, Sears TA (1982) The effects of single afferent impulses on the probability of firing of external intercostal motoneurones in the cat. J Physiol (Lond) 322:315-336.

Koch C, Rapp M, Segev I (1996) A brief history of time (constants). Cereb Cortex 6:93-101.

König P (1994) A method for the quantification of synchrony and oscillatory properties of neuronal activity. J Neurosci Methods 54:31-37.

Kustov AA, Robinson DL (1996) Shared neural control of attentional shifts and eye movements. Nature 384:74-77.

Laurent G (1996) Dynamical representation of odors by oscillating and evolving neural assemblies. Trends Neurosci 19:489-496.

Lisman JE (1997) Burst as a unit of neural information: making unreliable synapses reliable. Trends Neurosci 20:38-43.

Livingstone MS, Freeman DC, Hubel DH (1996) Visual responses in V1 of freely viewing monkeys. Cold Spring Harb Symp Quant Biol LXI $27-37$.

Lopez-Barneo J, Llinas R (1988) Electrophysiology of mammalian tectal neurons in vitro. I. Transient ionic conductances. J Neurophysiol 60:853-868.

Mainen ZF, Sejnowski TJ (1995) Reliability of spike timing in neocortical neurons. Science 268:1503-1506.

Mandl G (1993) Coding for stimulus by temporal patterning of spike discharges in visual cells of cat superior colliculus. Vision Res 11:1451-1475.

Metherate R, Cox CL, Ashe AH (1992) Cellular bases of neocortical activation: modulation of neural oscillations by the nucleus basalis and endogenous acetylcholine. J Neurosci 12:4701-4711.

Moore GP, Segundo JP, Perkel DH, Leviathan H (1970) Statistical signs of synaptic interaction in neurons. Biophys J 10:876-900.

Munk MHJ, Roelfsema PR, König P, Engel AK, Singer W (1996) Role of reticular activation in the modulation of intracortical synchronization. Science 272:271-274.

Murthy VN, Fetz EE (1992) Coherent 25- to $35-\mathrm{Hz}$ oscillations in the sensorimotor cortex of awake behaving monkey. Proc Natl Acad Sci USA 89:5670-5674

Murthy VN, Fetz EE (1996a) Oscillatory activity in sensorimotor cortex of awake monkeys: synchronization of local field potentials and relation to behavior. J Neurophysiol 76:3949-3967.

Murthy VN, Fetz EE (1996b) Synchronization of neurons during local field potential oscillations in sensorimotor cortex of awake monkeys. J Neurophysiol 76:3968-3982.

Nelson JI, Salin PA, Munk MHJ, Arzi M, Bullier J (1992) Spatial and temporal coherence in cortico-cortical connections: a cross-correlation study in areas 17 and 18 in the cat. Vis Neurosci 9:21-37.

Neuenschwander S, Singer W (1996) Long-range synchronization of oscillatory light responses in the cat retina and lateral geniculate nucleus. Nature 379:728-733.

Nowak LG, Munk MHJ, Nelson JI, James AC, Bullier J (1995) Structural basis of cortical synchronization. I. Three types of interhemispheric coupling. J Neurophysiol 74:2379-2400.

Palm G, Aertsen AMHJ, Gerstein GL (1988) On the significance of correlations among neuronal spike trains. Biol Cybern 59:1-11.

Parodi O, Combe P, Ducom JC (1996) Temporal coding in vision: coding by the spike times arrival leads to oscillations in the case of moving target. Biol Cybern 74:497-509. 
Pauluis Q (2000) Statistical signs of common inhibitory feedback with delay. Neural Comput 12:2513-2518.

Pauluis Q, Baker SN (2000) An accurate measure of the instantaneous discharge probability with application to unitary joint-event analysis. Neural Comput 12:687-709.

Pauluis Q, Baker SN, Olivier E (1999) Emergent oscillations in a realistic network: the role of inhibition and the effect of the spatiotemporal distribution of the input. J Comput Neurosci 6:27-48.

Perkel DH, Gerstein GL, Moore GP (1967) Neuronal spike trains and stochastic point process. II. Simultaneous spike trains. J Biophys 7:419-440.

Riehle A, Grün S, Diesmann M, Aertsen A (1997) Spike synchronization and rate modulation differentially involved in motor cortical function. Science 278:1950-1953.

Robinson DL, Kertzman CJ (1995) Covert orienting of attention in macaques. III. Contributions of the superior colliculus. J Neurophysiol 74:713-721.

Roelfsema PR, Singer W (1998) Detecting connectedness. Cereb Cortex 8:385-396.

Roelfsema PR, Engel AK, König P, Singer W (1997) Visuomotor integration is associated with zero time-lag synchronization among cortical areas. Nature 385:157-161.

Roucoux A, Crommelinck M (1976) Eye movement evoked by superior colliculus stimulus in the alert cat. Brain Res 106:349-363.

Sears TA, Stagg D (1976) Short-term synchronizaton of intercostal motoneurone activity. J Physiol (Lond) 174:295-315.

Silverman BW (1986) Density estimation for statistics and data analysis. London: Chapman \& Hall.

Singer W (1995) Development and plasticity of cortical processing architectures. Science 270:758-764.

Singer W, Gray CM (1995) Visual feature integration and the temporal correlation hypothesis. Annu Rev Neurosci 18:555-586.

Sparks DL (1986) Translation of sensory signals into commands for control of saccadic eye movements: role of the primate superior colliculus. Physiol Rev 66:118-171.
Steriade M, Amzica F, Contreras D (1996) Synchronization of fast $(30-40 \mathrm{~Hz}$ ) spontaneous cortical rhythms during brain activation. J Neurosci 16:392-417.

Traub RD, Whittington MA, Colling SB, Buzsáki G, Jefferys JGR (1996) Analysis of gamma rhythms in the rat hippocampus in vitro and in vivo. J Physiol (Lond) 493:471-484.

Usrey WM, Reid RC (1999) Synchronous activity in the visual system. Annu Rev Physiol 61:435-456.

Vaadia E, Haalman I, Abeles M, Bergaman H, Prut Y, Slovin H, Aertsen A (1995) Dynamics of neuronal interactions in monkey cortex in relation to behavioural events. Nature 373:515-518.

van Vreeswijk C, Abbott LF, Ermentrout GB (1994) When inhibition not excitation synchronizes neural firing. J Comput Neurosci $1: 313-321$

Wang XJ, Buzsáki G (1996) Gamma oscillation by synaptic inhibition in a hippocampal interneuron network model. J Neurosci 15:6402-6413.

White JA, Chow CC, Ritt J, Soto-Treviño C, Kopell N (1998) Synchronization and oscillatory dynamics in heterogeneous, mutually inhibited neurons. J Comput Neurosci 5:5-16.

Whittington MA, Traub RD, Jeffereys JGR (1995) Synchronized oscillations in interneuron networks driven by metabotropic glutamate receptor activation. Nature 373:612-615.

Whittington MA, Traub RD, Faulkner HJ, Stanford IM, Jefferys JGR (1997) Recurrent excitatory postsynaptic potentials induced by synchronized fast cortical oscillations. Proc Natl Acad Sci USA 94:12198-12203.

Wilson HR, Cowan JD (1972) Excitatory and inhibitory interactions in localized populations of model neurons. Biophys J 12:1-24.

Wollman DE, Palmer LA (1995) Phase locking of neuronal responses to the vertical refresh of computer display monitor in cat lateral geniculate nucleus and striate cortex. J Neurosci Methods 60:107-113.

Wurtz RH, Goldberg ME, Robinson DL (1982) Brain mechanisms of visual attention. Sci Am 246:124-135.

Zhu JJ, Lo F-S (2000) Recurrent inhibitory circuitry in the deep layers of the rabbit superior colliculus. J Physiol (Lond) 523:731-740. 